\title{
Entre la unión y la diferencia. Las representaciones de los intelectuales en las revistas culturales de Bahía Blanca en las primeras décadas del siglo $X X$
}

\author{
Between the union and the difference. \\ The representations of the intellectuals in the cultural \\ magazines of Bahía Blanca in the first decades of the 20th century
}

\author{
María de las Nieves Agesta ${ }^{1}$
}

\section{RESUMEN}

En el presente trabajo examinaremos las caricaturas personales de los intelectuales que fueron publicadas entre 1900 y 1920 en las revistas culturales de Bahía Blanca, una ciudad situada al sudoeste de la provincia argentina de Buenos Aires. De esta manera, analizaremos las representaciones que de sí mismos construyeron estos agentes a partir de la articulación entre los elementos textuales y visuales que posibilitaban los magazines. La imagen impresa -en especial, la caricatura, cuya fascinación sobre los lectores impulsó, en gran medida, la aparición y el sostenimiento de estos proyectos editoriales- y los textos literarios o periodísticos, contribuyeron a construir una imagen de estos nuevos "intelectuales" $y$ de sus diferencias internas a medida que su labor se profesionalizaba y se iba configurando un campo cultural con sus particularidades locales.

Palabras clave: Intelectuales. Representaciones. Revistas culturales. Modernización. Bahía Blanca.

\section{ABSTRACT}

This article examines the personal caricatures of the intellectuals that were published between 1900 and 1920 in the cultural magazines of Bahía Blanca, a southwestern town located on the argentine province of Buenos Aires. In this manner, we will analyze the representations that these agents built of themselves based on the articulation between the textual and visual elements that magazines made possible. The

1 Centro de Estudios Regionales "Prof. Félix Weinberg"-UNS / CONICET. Una versión preliminar de este artículo fue presentada y debatida en las XIII Jornadas Interescuelas. Departamento de Historia, organizado por el Departamento de Historia de la Facultad de Humanidades de la Universidad Nacional de Catamarca durante los días 10 a 13 de agosto de 2013. Agradezco los oportunos comentarios que me realizaron en esa ocasión. 
impressed image -specially, the caricature whose fascination on the readers favoured the emergence and the existence of these editorial projects- and the literary or journalistic texts, contributed to construct a representation of the new "intellectuals" and their internal differences as the professionalization process developed and the cultural field took form which its local features.

Keyword: Intellectuals. Representations. Cultural magazines. Modernization. Bahía Blanca.

Durante las primeras décadas del siglo xx, la ciudad de Bahía Blanca situada al sudoeste de la provincia de Buenos Aires fue protagonista de un proceso de modernización acelerada estrechamente vinculado a su consolidación como nodo ferro-portuario que, desde fines de la centuria anterior, le permitió insertarse exitosamente en el modelo agroexportador impulsado por el gobierno nacional. ${ }^{2} \mathrm{El}$ crecimiento material y demográfico que, a partir de entonces, se produjo en la localidad tuvo su correlato en el ámbito cultural. Bahía Blanca se convirtió en polo de atracción de inmigrantes entre los cuales arribaron profesionales de otras regiones para desempeñarse en las dependencias institucionales o seducidos por las "promesas" de desarrollo del nuevo centro económico. Las inquietudes intelectuales de estos recién llegados fueron vehiculizadas por la actividad periodística: así los periódicos facciosos que proliferaron en las décadas de 1880 y 1890, fueron cediendo terreno ante una prensa más moderna y diversificada, atravesada por las contradicciones y las dificultades propias del medio. En ella, intervinieron poetas, periodistas y profesionales liberales en un intento por configurar una esfera pública de participación acorde al modelo civilizatorio europeo. En el transcurso de los primeros años del siglo xx, la aparición de nuevos formatos implicó también la consolidación de diferentes modos de intervención que supusieron una cada vez más marcada distinción entre estos mismos productores intelectuales.

Precedida sólo por un semanario ilustrado, en 1902 apareció la primera revista publicada en la ciudad. A ella siguieron otras publicaciones literarias, sectoriales y de interés general -los magazines- donde una relación inédita entre imágenes y textos introducía una nueva dinámica de producción y de consumo culturales. Las caricaturas, fotografías e ilustraciones reproducidas gracias a las nuevas tecnologías de impresión se sumaron así al espacio urbano y cotidiano, modificando los modos de mirar y de leer de los habitantes.

En el presente trabajo examinaremos las caricaturas personales de los productores culturales locales que fueron publicadas en las revistas bahienses entre 1900 y 1920 a fin de analizar las representaciones (CHARTIER, 1990) que de sí mismos construyeron estos agentes a partir de la articulación entre los elementos textuales y visuales. ${ }^{3}$ La imagen

2 Con este nombre se conocer el modelo económico impulsado por la Generación del ‘ 80 en la Argentina que suponía la inserción del país en el mercado internacional como exportador de materias primas y receptor de productos manufacturados y de capital. La economía agroexportadora o de crecimiento hacia afuera se sostuvo como sistema hegemónico hasta 1930, momento en que sus propias limitaciones y la crisis internacional exigieron una reformulación del modelo (ROCCHI, 2000, p. 15-69).

3 No es nuestra intención realizar aquí una reflexión teórico-metodológica acerca de la utilización de las caricaturas en la investigación histórica. Al respecto véase (AGESTA, 2009). 
impresa -cuya fascinación sobre los lectores impulsó, en gran medida, la aparición y el sostenimiento de estos proyectos editoriales- funcionó, a su vez, para delinear una imagen de estos nuevos "intelectuales" y de sus diferencias internas a medida que su labor se profesionalizaba y se iba configurando un campo cultural cuyas particularidades locales cuestionan el alcance de las matrices interpretativas totalizadoras.

\section{Intelectuales: entre la unión y la diferencia}

Hablar de los "intelectuales" requiere siempre de mayores precisiones que las que supone la mera apelación al sentido común formado a partir de una larga tradición de uso cuyos orígenes se remontan hasta el siglo XIX europeo. ${ }^{4}$ En el presente trabajo utilizaremos el concepto de "intelectuales" en un sentido amplio para referirnos a un grupo social moderno dedicado a la producción y administración de bienes simbólicos que ha asumido para sí la misión de intervenir en la vida pública, legislando ${ }^{5}$ sobre cuestiones políticas, morales o estéticas y amparados por la autoridad que les confiere el acceso al conocimiento. Debiéramos decir, también, que la posición de estos agentes se encuentra siempre en la tensión entre la autonomía relativa -que le otorga la posesión de un saber específico y de sus propios mecanismos de consagración y legitimación- y su dependencia respecto de las fuerzas políticas y económicas. En efecto, la relación con el Estado y con el Mercado ha permeado el accionar y las representaciones de los intelectuales desde sus orígenes. Julio Ramos en Desencuentros de la modernidad en América Latina: Literatura y política en el siglo XIX (RAMOS, 2003) y Ángel Rama en La ciudad letrada (RAMA, 2004), entre otros, han explorado ambos nexos destacando la especificidad de la realidad latinoamericana vinculada a la experiencia colonial, a la retórica del modernismo y las particularidades del desarrollo profesional inserto en un proceso de modernización desigual. ${ }^{6}$

En el caso de Bahía Blanca, localidad situada al sudoeste de la provincia de Buenos Aires, la mentada autonomización pregonada desde los discursos letrados debió enfrentarse a las contradicciones propias de un núcleo en crecimiento alejado de los centros de creación y consumo cultural del país y del mundo. La existencia de un mercado lector reducido y la

\footnotetext{
$4 \mathrm{Si}$ bien no es nuestra intención intervenir en el debate sobre los sentidos de este concepto, remitimos a los orígenes de su uso tal cual lo ofrecen los investigadores de la historia y la sociología de los intelectuales que remontan el uso sustantivado del término al episodio que en 1898 movilizó a los franceses en torno al “caso Dreyfus”. En su J'accuse, Émile Zola congregó a escritores y universitarios que al consignar sus credenciales junto a sus firmas afirmaron la autoridad y la responsabilidad moral de los letrados para intervenir en el debate cívico. Véanse por ej. (ALTAMIRANO, 2002, p. 48-49; CHARLE, 2009).

5 La metáfora del legislador es propuesta por Zygmunt Bauman para referirse a la estrategia moderna del trabajo intelectual en oposición a las prácticas típicamente posmodernas que se condensan en la figura del intérprete(BAUMAN, 1997).

6 El concepto de modernización desigual le permite a Ramos, por un lado, explorar la literatura latinoamericana durante su período de emergencia como "un discurso que intenta autonomizarse, es decir, precisar su campo de autoridad social; y por otro, el análisis de las condiciones de imposibilidad de su institucionalización." (RAMOS, 2003, p. 12).
} 
dependencia respecto de los recursos tecnológicos y editoriales de la capital, acrecentaban, sin dudas, las dificultades para la configuración de un campo intelectual relativamente autónomo. ${ }^{7}$ En efecto, aunque en expansión, el número de lectores no alcanzaba para sostener tiradas masivas de varios periódicos y, menos aún, de revistas, tal como sucedía en Buenos Aires. Incluso en el caso de los nuevos formatos periodísticos introducidos por los grupos letrados, la convivencia del sistema de suscripción con el de venta directa se mantendría durante todo el período marcando el carácter mixto de tales emprendimientos. ${ }^{8}$ Parafraseando a Jorge Rivera (1998), la "fundación material de la ilustración" bahiense, sobre todo en lo que a las imprentas se refiere, sería igualmente tardía y se concentraría en torno a los grandes diarios o a algunas casas impresoras que, por añadidura, no contaban con los últimos adelantos de orden técnico. ${ }^{9}$ De esta manera, los editores de publicaciones ilustradas se veían obligados a recurrir a las imprentas porteñas, con las demoras y el aumento de costos que esto implicaba. Estas estrategias y el impulso otorgado por el grupo activo de profesionales y letrados llegados a la ciudad a principios del siglo, permitieron sortear muchos de estos obstáculos para constituir un rico y variado panorama periodístico. ${ }^{10}$

Si las condiciones se presentaban poco favorables para las publicaciones periódicas, menos aún lo eran para la edición de libros. Recién en 1912 se publicaría la primera obra de factura local titulada La Senda de la Vida de Francisco Pablo de Salvo. A ella seguirían Poesías de Clotilde Buceta en 1913, Notas y acentos de Eduardo Bambill en 1915, Hojas sueltas de Francisco Rosito en 1917, Chispas de De Salvo en 1918 y En busca del olvido de Ovidio Martínez en 1919. A estos seis títulos editados en la década del 1910, se sumarían dieciséis en el decenio siguientes (TUMA; BERMEJO HURTADO; BLANCO DE ANTA, 1982, p. 151-175). ${ }^{11}$ Aunque en crecimiento, estas cantidades indican la imposibilidad de que los escritores hicieran de la literatura su medio de vida: su supervivencia se veía supeditaba, entonces, a

7 Esta afirmación nos lleva, una vez más, a reflexionar sobre las relaciones entre los centros de producción simbólica y las áreas más alejadas de ellos. En efecto, el concepto de "periferia de la periferia" ha sido utilizado en muchas ocasiones para definir la situación cultural de las ciudades del Interior del país en relación de doble subordinación respecto de los centros de producción europeos y de Buenos Aires. Si bien coincidimos con las objeciones que este modelo se han realizado en tanto suponía una adopción acrítica y pasiva de modelos, creemos que renunciar al concepto de periferia implicaría desconocer las desigualdades de poder que efectivamente existían en el momento considerado y que funcionaban también como horizonte de pensamiento para los agentes sociales. Preferimos, entonces, pensar estos territorios como ámbitos periféricos activos a la vez que como centros irradiadores, dependiendo de las circunstancias socio-históricas en las cuales se desarrollaron. Hablar de lo periférico en lugar de la periferia nos permite concebir las posiciones como instancias móviles y no como esencias que definen las prácticas de los espacios regionales o locales.

8 Para un análisis del crecimiento del público lector véase (AGESTA, 2010).

9 Para una historia de las imprentas en Bahía Blanca, véase (MATIJEVIC, 1978).

10 Hasta el momento hemos contabilizado, en el período comprendido entre 1900 y 1930, la existencia de, al menos, ochenta publicaciones que abarcaban desde diarios y periódicos informativos de diferentes vertientes ideológicas hasta las novelas semanales de la década de 1920, pasando por una amplia variedad de revistas ilustradas, literarias, corporativas o nacionales.

11 Cabe destacar que varias de las obras registradas por las autoras formaron parte, en realidad, de colecciones de novelas semanales publicadas en la ciudad entre 1921 y 1923. Beatriz Sarlo (2000) y Margarita Pierini et al. (2004) han dado cuenta del fenómeno de las novelas por entregas y de su amplia difusión en Buenos Aires desde fines de la década del 10 a partir de sus análisis de La Novela Semanal y en relación con el proceso de modernización cultural porteño. En Bahía Blanca, fue durante la década del 20 que se impuso definitivamente el género de la novela semanal con la aparición de La Novela del Sud dirigida por Bruno Alvarado y Humberto Grossi en 1921, La Novela Moderna de Andrés Moreno Neuroni y Eusebio Heredero Clar y La Novela Bahiense (también a cargo de Bruno Alvarado) en 1922 y La Novela del Día en 1923. 
su inserción en la burocracia estatal, en los ámbitos educativos, en el periodismo o en todos ellos a la vez.

Poesías y narraciones eran publicadas eminentemente en las páginas de las revistas literarias o ilustradas ${ }^{12}$ y, junto a ellas, crónicas, críticas y notas de actualidad, constituían la mayor parte de la producción de estos intelectuales. Los libros, por su parte, eran editados en imprentas porteñas que podían asumir los riesgos económicos de tales empresas. Sombras, poemario de Fernando García Monteavaro aparecido en Buenos Aires en 1905, es un claro ejemplo de ello. Conocido hasta entonces por su intensa labor periodística como director y colaborador de las revistas Letras (1906), Proyecciones (1909-1910) y Ecos (1910-1911) y del Diario de la Tarde (1911-1912), Monteavaro encontraba, así, la ocasión de presentarse ante su público como un escritor renombrado, inclusive en la Capital. Que la publicación y el reconocimiento metropolitano funcionaban como mecanismos de legitimación simbólica, parece asegurarlo el artículo "Un poeta, señora" de Martín Rafael Berutti que Monteavaro publicó en Ecos el 4 de marzo de 1911. Durante casi dos páginas, Berutti desplegaba un panegírico dedicado a Sombras y a su autor, diciendo

\begin{abstract}
Yo conozco un libro del trovador de que os hablo. Se titula Sombras. Todo él es un catecismo de dolor y de excepticismo. Cuando lo recibí casi no lo leo. Pensaba que hallaríame con versitos de un muchacho desconocedor de la vida y, sin embargo, desengañado. Pero Sombras me deslumbró. Hay en ellas mucha luz. Cierto es que, en el fondo hay algo de Bécquer y de Acuña. Pero dejemos esto para los apergaminados sacerdotes de la crítica moderna... (doy mucha importancia a estos suspensivos). Debéis saber que, como se ha dicho por ahí, se puede ser hijo de alguien sin dejar de ser uno mismo. (ECOS, 4 mar. 1911, p. 6) ${ }^{13}$
\end{abstract}

Para afirmar, luego de una citar uno de sus poemas: "Sí, decís bien, es precioso y de Monteavaro. Es él, señora, mi poeta. Fernando García Monteavaro. En Bahía Blanca, un ejemplo. En cualquier parte, un artista que sabe tejer bellas filigranas." Si estos párrafos operaban como una certificación de la calidad poética del autor de Sombras fundada en la originalidad tanto como en las filiaciones literarias, no es menos cierto que constituían una afirmación de la posibilidad de ser un "escritor en las orillas". En cualquier lugar, incluso en una localidad alejada como la bahiense, podía surgir un artista cuyo mérito no se agotara en el talento sino que se extendiera a sus rasgos personales convirtiéndolo en un modelo a seguir.

\footnotetext{
12 En Bahía Blanca, a diferencia de lo que sucedía en otras ciudades del país, no puede establecerse una clara distinción entre las revistas ilustradas y las literarias. En efecto, mientras las primeras caracterizadas por el componente visual, incluían siempre producciones literarias en prosa o en verso, las segundas incorporaban en todas las ocasiones la dimensión visual a partir de los elementos tipográficos y de la creciente introducción de ilustraciones y fotografías. La diferencia no puede establecerse, entonces, sino en términos de énfasis sobre uno u otro aspecto. 13 En todos los casos se respeta la ortografía original. El resaltado es nuestro.
} 
El texto de Berutti señalaba, además, una diferenciación interna dentro del mundo literario que oponía los escritores a las nuevas figuras del campo: al editor, que hasta entonces personificaba la tiranía del mercado, ${ }^{14}$ se sumaban los "apergaminados sacerdotes de la crítica moderna" que, si bien en Bahía Blanca tenían una existencia meramente nominal, contribuían a crear una representación de artista moderno. Así, Monteavaro, cuya labor permaneció siempre ligada al ámbito del periodismo, elegía presentarse a sí mismo como "poeta" y diferenciarse, de este modo, de los trabajadores de la prensa. Al igual que él, los escritores buscarían distanciarse cada vez más de los periodistas quienes, por su parte, comenzarían a organizarse en formaciones e instituciones específicas y a definir los rasgos de un discurso especializado. Como señala Alejandra Laera, al analizar el proceso de profesionalización de la escritura se ha equiparado la actividad periodística y la literaria. Sin embargo, y sobre todo a partir del Centenario, la creciente especialización dentro del periodismo y las diferencias en los modos de acceso, las formas de agrupación y los vínculos con el mercado conllevarían una progresiva distinción entre ambas tareas (LAERA, 2008, p. 495-522).

En esta instancia, trazar fronteras resultaba más urgente que fortalecer los vínculos entre los miembros de la elite letrada. Tal vez en ello se fundara el rechazo al término genérico "intelectual" como mecanismo de identificación: si la palabra era, según Bauman, un "toque de reunión", los protagonistas preferían dar cuenta de la dispersión que se ocultaba bajo la aparente unidad. Las revistas culturales, dispositivos en torno a los cuales se reunían y se organizaban los círculos letrados, asumieron esta voluntad de diferenciación a partir de sus recursos específicos -gráficos o discursivos- en especial durante la década del 1910. El sustantivo "intelectuales" apareció en este contexto raramente y, cuando lo hizo, fue utilizado con una carga de sentido negativa más próxima a la tradición anglosajona enunciada por Raymond Williams que a la representación francesa ligada al compromiso. ${ }^{15}$

La oposición entre "los supuestos intelectuales" y los verdaderos hombres de letras quedó de manifiesto en el artículo de Héctor de Villiers publicado en Arte y Trabajo, bajo el título de "Los intelectuales". Allí, de Villiers sostenía que

Un producto genuino de nuestro medio inferior, constitúyenlo los "intelectuales". No me refiero, claro está, a los que dedican todas sus energías, toda su vida a la meditación y al estudio, y que han producido y producen las obras admirables que honran permanentemente a la

14 Trabajamos sobre la representación del editor y del tipógrafo a propósito de Luz y Sombras (1902). Esta revista, primera de la ciudad, se ocupó en diversas ocasiones de retratar a los nuevos agentes del incipiente campo intelectual y las conflictivas relaciones que solían establecerse entre ellos. Allí, el editor era presentado como el símbolo de las presiones tiránicas que el mercado ejercía sobre los escritores. El tipógrafo, por su parte, era criticado por la naturaleza mecánica de su actividad cuya estrecha asociación con el carácter productivo del mundo intelectual resultaba incompatible con la volubilidad de la inspiración literaria (AGESTA, 2007).

15 Una excepción en este sentido fue el uso que hizo de ella la mencionada Luz y Sombra. Podemos conjeturar que el carácter incipiente del campo cultural en 1902 tornaba necesario fortalecer la cohesión de la "intelectualidad bahiense" a la cual el semanario se dirigió expresamente. 
humanidad. Los "intelectuales" de que me voy a ocupar, son justamente su antítesis: no estudian ni meditan. No podrían tampoco hacerlo, por las particularidad de su organización psíquica. Usurpan el calificativo que no obtendrían jamás por la calidad de sus obras. Inteligencias mediocres, inferiores al término medio, con deformaciones hereditarias, en los momentos culminantes de sus crisis, siente la necesidad de escribir. Es la manera como se manifiesta el irremediable automatismo que rige su actividad superior: es la ausencia del ritmo funcional del organismo, al operarse en él las transformaciones energéticas que son la razón de su existencia; es la ausencia de poderes inhibitorios, que mantengan el equilibrio de las facultades y que economicen el esfuerzo; es la fatal y triste consecuencia de la abulia, que hace del ser una veleta que oscila a todos los vientos e impide la formación de la personalidad.(ARTE Y TRABAJO, 30 abr. 1918, p. 26).

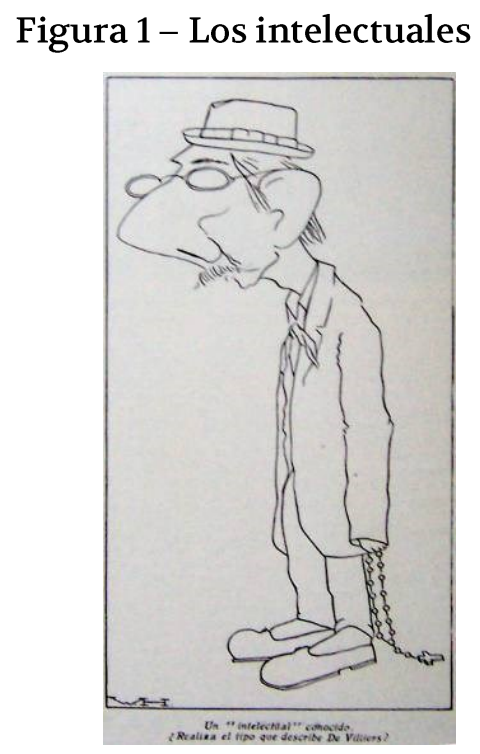

Fonte: Arte y Trabajo, 30 abr. 1918, p. 26.

Inteligente e intelectual eran términos opuestos. El primero designaba a quienes trabajaban concienzudamente por el progreso de la humanidad; equilibrados y abocados a las tareas del espíritu, la calidad de sus obras coincidía siempre con sus cualidades morales. El segundo, daba cuenta de los que se dedicaban a las Bellas Letras eran confundidos por sus pasiones y por sus deficiencias mentales que los conducían a la escritura por caminos erróneos que culminaban en el fracaso literario. De Villiers recuperaba argumentos biologicistas sustentados en la teoría de la degeneración para explicar las diferencias dentro del mundo letrado. El desenfreno de los deseos asociados a un raciocinio débil que no lograba someterlos era el fundamento de la mediocridad literaria. Una sexualidad aberrante e incontrolada explicaba la profusión de poemas amorosos y de divagaciones místicas que la misma evolución social se iba a encargar de eliminar. Con una original combinación de 
elementos organicistas, racionalistas y positivistas de Villiers trazaba una línea demarcatoria entre los buenos y los malos literatos.

Ahora bien, ¿quiénes quedaban de uno u otro lado de la frontera? Ningún nombre se mencionaba en el texto, pero la imagen incorporada por la dirección de Arte y Trabajo resultaba más que elocuente en este sentido. (Figura 1) La caricatura de William Herther (seudónimo de Emilio Juan Valla) ${ }^{16}$ mostraba a un personaje ridículo acompañado por un epígrafe que decía: “Un 'intelectual' conocido. ¿Realiza el tipo que describe De Villiers?”. Con un saco demasiado grande para su cuerpo, los antejos y el sombrero demasiado pequeños para su cabeza y la nariz y la oreja desmesuradas para su rostro, esta imagen representaba la figura del literato bobalicón, perdido en sus propios delirios y carente de toda sensatez y sentido práctico. A las características generales que ilustraban lo dicho en el texto, Herther le sumaba ciertos atributos personales que permitían identificar con facilidad al personaje. Su fisonomía y el rosario colgando indolente de su mano izquierda, aludían a Francisco Pablo de Salvo, escritor cuyo libro había sido recientemente publicado, colaborador frecuente de las revistas y periódicos bahienses vinculado a la Iglesia Católica a partir de su nexo con el Círculo Católico de Obreros y su adhesión a los principios de la Rerum Novarum.

Figura 2 - William Herther

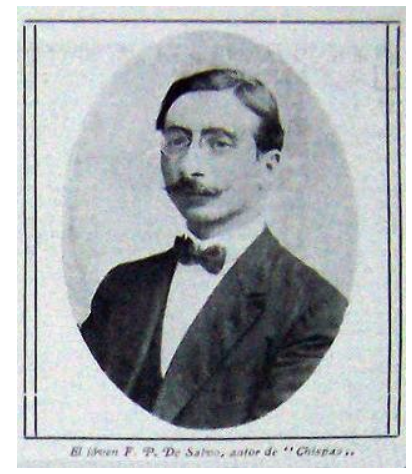

Fonte: Arte y Trabajo, 20 abr. 1918, p. 19.

16 Valla se desempeñó como periodista en los diarios Bahía Blanca, El Atlántico y La Nueva Provincia. De acuerdo al relato de Germán García, "era un hombre de muy sólida preparación científica y humanística. Severo consigo mismo, no escribía nada superficial; aprendió alemán para estudiar filosofía y se documentó en los textos más modernos para sus editoriales sobre temas económicos. Le apasionaba la ciencia y formó una valiosísima biblioteca. Los comentarios de Valla sobre conciertos y exposiciones pictóricas eran enjundiosos." Esta descripción nos permite conjeturar una consonancia de opiniones entre Valla y Villiers que fundamentaría su colaboración gráfica. Vinculado a las actividades científicas modernas, probablemente compartía con el autor la antipatía por estos místicos del pensamiento y los argumentos a partir de los cuales se impugnaban sus obras (GARCÍA, 1978, p. 83). 
Para ahuyentar cualquier duda al respecto, el número siguiente de Arte y Trabajo incorporó en sus páginas una fotografía del caricaturizado y una crítica adversa de Chispas, su libro editado en 1912. [Figura 2] Del autor y de su obra decía "Rea Silvia": "Tomito que se lee un éxito para la venta y por lo tanto para su autor el joven Francisco Pablo de Salvo. No le llamaré intelectual, el vocablo ha caído en deplorable desuso á fuerza de hacerlo servir lo mismo para un fregado que para un barrido." (ARTE Y TRABAJO, 20 abr. 1918, p. 19) Llama la atención el ensañamiento de la revista de Janelli con De Salvo, sobre todo si se considera la filiación que ambos compartían con los sectores católicos. A modo de hipótesis, puede pensarse que tales reproches realizados desde 1918 en adelante, se fundaban en un cambio de modelo intelectual que elevaba al científico por sobre el creador espiritualista. ${ }^{17} \mathrm{La}$ estética modernista que se expresaría por última vez de forma orgánica en Azul-revista de número único que aparecería en 1919 bajo la dirección de Ramón P. J. Rossignol y F. Silva D'Herbil- comenzaba a ceder terreno ante la literatura naturalista y psicologista de corte positivista (CHARLE, 2009) ${ }^{18}$.

Por otra parte, a diferencia de las anteriores, Arte y Trabajo no se hallaba bajo la dirección de un grupo de literatos sino de un empresario impresor como Miguel Janelli. Sin dudas, esto influyó sobre su representación negativa de parte del mundo intelectual. Luz y Sombras (1902), Letras (1906), Letras y Figuras (1908), Proyecciones (1909-1910) y Ecos (19101911), por el contrario, habían sido proyectos encabezados por escritores cuya preocupación, más que fijar los límites de la buena y la mala literatura, había recaído en la afirmación de su imagen de artistas y en su diferenciación de los demás productores simbólicos: periodistas, dilettantes y profesionales liberales. ${ }^{19}$

\section{El periodista, del empresario al obrero}

Las reflexiones sobre el periodismo y los periodistas pueden rastrearse en los medios locales desde el siglo XIX. Sin embargo, hacia principios de la siguiente centuria la preocupación por definir la misión, el estilo y el perfil de los trabajadores de la prensa se volvió omnipresente. El común reconocimiento de la importancia que el periodismo estaba adquiriendo en la ciudad y en el mundo, suscitaba intensos debates que partían, muchas veces, de la comparación entre las formas de escritura, los mecanismos editoriales y los contenidos de las publicaciones informativas y aquéllos propios de la literatura. Ante las

17 El espiritualismo era una corriente de pensamiento filosófico-literaria que planteaba el desplazamiento de la centralidad concedida al positivismo cientificista para colocar allí al escritor, a su mundo interior y a los valores religiosos, morales y estéticos. Como afirma Oscar Terán, en el Río de la Plata la influencia espiritualista se articuló en torno al modernismo literario, al hispanoamericanismo y a la prédica antiimperialista (TERÁN, 2000).

18 La oposición ciencia/espíritu polarizó el debate durante todo el período considerado. Hacia los años 20, el eje de la razón pareció imponerse sobre la pasión como fundamento de las intervenciones intelectuales (MONTALDO, 1994).

19 Por razones de espacio, aquí sólo nos ocuparemos de la diferenciación entre poetas y periodistas. 
reiteradas críticas a la superficialidad de los textos y a las falencias gramaticales o sintácticas, los mismos periodistas intentaron definir un "estilo diarista" que los diferenciara de las letras. La Revista Comercial dirigida por Ricardo Ducós, publicó varios artículos en este sentido. En "La Universidad del mundo. El periodismo. Consideraciones", la publicación de Ducós sostenía que

La misión del periodista, más importante aparece cada día: mayor campo se le abre gradualmente. La literatura es intrínsecamente la más noble de las artes; no es ella empero la que está elevando la mente refinando los gustos del pueblo. Ella no emplea el lenguaje familiar. Continúa habitando las cimas de Helicona, desdeñosa de bajar a las ranuras y en la llanura, en donde está la agitación humana, me verá el periodismo, simpatizando con el pueblo y fomentando en él, poco a poco la afición al estudio y el amor al saber. Así es que el periodismo, hablando en lenguaje llano y liso, de todo cuanto a todos interesa, ocupándose primero de lo más urgente, alerta todo lo presente y lo pasado, háse erigido por derecho propio, en universidad del mundo. (REVISTA COMERCIAL DE BAHÍA BLANCA, 8 fev. 1905, p.15).

Ciertamente esta mirada laudatoria del oficio no era compartida por los escritores que, unos años más tarde, advertían sobre la "vergonzosa bancarrota moral" (ECOS, 1 abr. 1911, p. 4) que afectaba al periodismo bahiense, muchas de cuyas "hojas nefandas le encaminan hacia la degradación moral, hacia la ruina, hacia la discordia”. (ECOS, 3 dez. 1910, p. 21) Los reproches o, en ocasiones, las reservas de los poetas frente al uso del lenguaje o al ejercicio de esa profesión provenían de la sujeción de la prensa a las reglas del mercado. Era la imperiosidad de la edición diaria o periódica la que imponía una escritura menos pulida y esmerada; la preocupación por atraer la atención del público y la competencia con otros medios, lo que orientaba la elección temática hacia noticias sensacionalistas, morbosas o hacia el chisme. La acusación de "materialismo", tópico espiritualista - más específicamente, arielista - ${ }^{20}$, resonaba frecuentemente en los discursos letrados al referirse al ejercicio periodístico. De allí se desprendían los principales defectos que con él se identificaban. Los periodistas, ávidos de la última noticia,

son soldados que, por necesidades de ver, están diariamente con el arma al brazo. Si les causáis algún mal, estad seguros que el rato menos pensado los índices pondrá, exhibiéndoos ridículamente ante la sociedad entera. El periodista es León y zorro; á veces se mantiene

20 Mediante el término "arielismo" se hace referencia a la corriente intelectual originada a partir de la publicación del Ariel de José E. Rodó en 1900. En ella el autor planteaba la antinomia Estados Unidos/América como expresión del par materia/espíritu. Recuperando la tradición grecolatina y revalorizando la hispanocristiana, Rodó rechazaba la mercantilización del mundo y apelaba al "registro aristocratizante del modernismo en búsqueda de algunos espacios protegidos de su conversión en valores de cambio. Uno de esos núcleos cree hallarlo en las juventudes latinoamericanas." (TERÁN, 2000, p. 349). 
tranquilo, con la majestad del rey de las selvas; y á veces husmea para mirar el terreno que pisa, cuando así le es conveniente (ARTE Y TRABAJO, 31 maio 1923, p. 18).

Estas representaciones los equiparaban a soldados, leones y zorros, implicaban un reconocimiento al poder de la prensa en la sociedad moderna pero también una advertencia contra la amoralidad de ciertas prácticas que la caracterizaban: por la primicia o en defensa de sus intereses, el periodista estaba dispuesto a la traición, a la ridiculización, a la calumnia.

Figura 3 - Juan A. Cámara

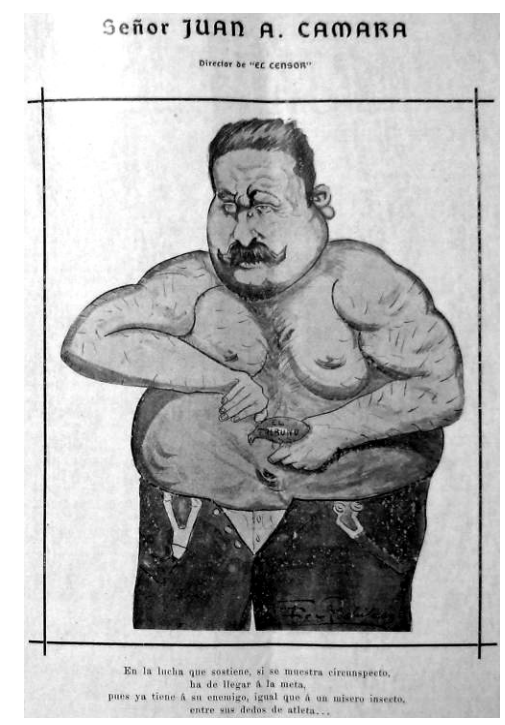

Fonte: ECOS, 18 mar. 1911, p. 14.

La caricatura que Francisco Rodríguez realizó para Ecos el 18 de marzo de 1911, enfatizaba la vulgaridad y el carácter grotesco de las luchas periodísticas por medio del enfrentamiento entre el diario conservador El Censor y el radical El Tribuno. Mientras éste último estaba encarnado en una garrapata, el primero se encontraba personificado en la figura desagradable de su director, Juan A. Cámara. ${ }^{21}$ Nada más alejado de la distinguida figura del poeta que este hombre sin camisa, con la bragueta del pantalón desprendida, los tirantes caídos, los ojitos taimados, el torso obeso y peludo y, por si algo faltaba, una verruga sobre la cara izquierda de su nariz. A diferencia con lo que ocurría en el caso de De Salvo, el cuerpo estaba sobredimensionado respecto de la cabeza. La fuerza física (lo material) primaba sobre lo intelectual (el espíritu) que había servido -por vía hiperbólica- para identificar al escritor.

21 Juan A. Cámara ya había sido caricaturizado en otras ocasiones, de manera igualmente desaprobatoria. Hoja del Pueblo en su número aniversario de 1910, había publicado una caricatura de "CARO" en la que se mostraba al director de $E I$ Censor recortando y pegando artículos de otros diarios. El pie de imagen decía: "Con tan excelente secretario/ es muy fácil escribir un diario". La denuncia de plagio, además de reforzar la crítica moral a Cámara, denotaba una creciente conciencia de los derechos de autoría y una valoración de la producción intelectual como actividad laboral. 
Figura 4 - Francisco Rosito

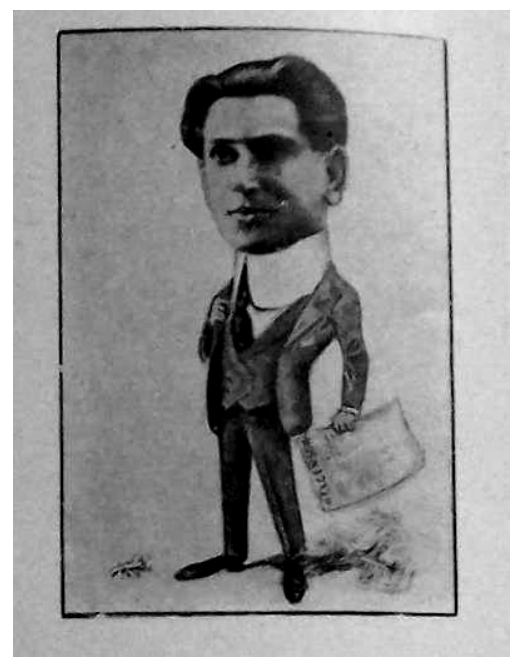

Fonte: Arte y Trabajo, 31 jan. 1920, p. 22.

Por supuesto, no todas las imágenes de periodistas respondían al perfil de la de Juan Cámara. También existían dignos representantes de la profesión cuya capacidad intelectual y moral no era puesta en duda. Así sucedía, por ejemplo, con la caricatura de Francisco Rosito realizada por José Cors para Arte y Trabajo. [Fig. 4] Como dijimos con anterioridad, esta mirada más favorable ante el periodismo coincidió con la progresiva transformación de la figura del intelectual pero también con el carácter diferencial de la revista de Janelli que, a diferencia de Ecos, no era una publicación liderada por literatos sino por un empresario gráfico, más próximo al mundo de la periodismo que al de las letras. En el caso de Rosito, nos encontramos ante un joven vestido pulcramente y a la moda que sostenía con fuerza el diario entre sus dedos. La expresión de su rostro, segura e inteligente, denotaba el carácter firme y emprendedor con que llevaría adelante la tarea periodística. Nada de romanticismo en su gesto ni en su porte. Los delirios del poeta que le había valido la crítica a De Salvo habían sido desplazados aquí por el sentido práctico y el dinamismo del administrador. Si bien al igual que aquél, la desproporción de la cabeza sugería el desarrollo de sus capacidades mentales, es interesante observar que, desde el punto de vista formal, Cors optó por una composición compleja que combinaba dibujo y fotografía. Esta suerte de fotomontaje, que había sido experimentado en las revistas ilustradas bahienses desde 1911 pero que gozaba de una larga tradición en Europa, ${ }^{22}$ le otorgaba a la caricatura un tono amable y hasta laudatorio ya que se prescindía de la deformación intencional de los rasgos

$22 \mathrm{El}$ primer fotomontaje que hemos registrado en las revistas ilustradas de Bahía Blanca fue publicado en Ecos el 4 de marzo de 1911. Con la aclaración de que se trataba de una "caricatura fotográfica", el dibujante anónimo representó al juez de paz y agrimensor masón Enrique Fretín. Poco después, en la misma publicación, apareció un segundo montaje dedicado al agente de la empresa "La Liverpool" y causeur literario, el señor G. P. Ivancich. En todos los casos, era la cabeza la fotografiada mientras que el cuerpo y los demás atributos que lo acompañaban se hallaban siempre dibujados. 
con una intención humorística para volver la representación lo más verosímil posible y asegurar, así, la identificación del personaje.

Si la representación gráfica de los empresarios periodísticos había oscilado entre la vulgaridad del negociante inescrupuloso construido por la mirada romántica y la dignidad del joven emprendedor promovido por los sectores progresistas, la imagen de quienes escribían con frecuencia en diarios, periódicos y revistas se articularía, en ambos casos, en torno a la figura del obrero. Luis Urbina en Arte y Trabajo, sostenía al respecto:

El periodista no es - ya se sabe- autor ni un poeta. No mide ni proporciona el trabajo; no lo amerita ni calcula; y tampoco, sobre excitado, hunde su cabeza en rebuscamientos y delirios. No es precisamente un pensador ó un artista. Es, debe ser, un obrero hábil, que sabiendo pensar y sentir, está obligado á poner en su obra, sólo pequeña dosis de ideas y de emoción, la necesaria para que el resultado de su faena alcance la duración de la rosa del verso antiguo; el espacio de una mañana (ARTE Y TRABAJO, 20 fev. 1918, p. 19).

Sometido a los "trabajos forzados de la literatura semanaria", el artesano de la palabra se encontraba sujeto a la tiranía de del mercado periodístico y de sus representantes (el editor, el tipógrafo) y, por ello, su posición podía asimilarse a la de un asalariado industrial. No era el genio el que se manifestaba en sus textos, sino la habilidad casi artesanal de quien reiteraba una y otra vez los mismos procedimientos con "pequeñas dosis de ideas y de emoción". A la sensibilidad desbordante del poeta modernista, debía oponer la racionalidad, la sencillez y la concisión del discurso informativo, crítico o ensayístico.

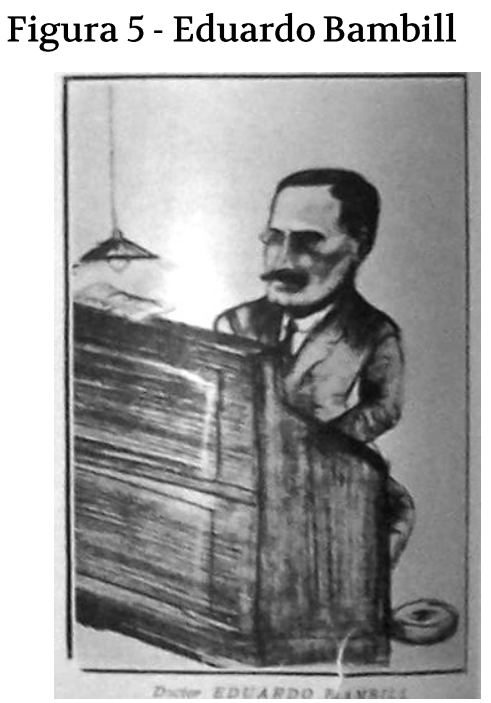

Fonte: Arte y Trabajo, 30 ago. 1917, p. 8. 
También en Arte y Trabajo, el canillita José Cors retrató a Eduardo Bambill, abogado radical y periodista de trayectoria, en su mesa de trabajo. La torpeza de los trazos -mucho más cuidados en el tratamiento del rostro- ${ }^{23}$ no impedía reconocer en la caricatura a Bambill, personaje conspicuo de la ciudad. En un amplio escritorio, con una lámpara baja enfocando el lugar de escritura y con una actitud severa y concentrada, se veía al periodista como una figura compuesta y austera, cuya vocación intelectual no excluía la pulcritud y la sensatez que revelaba su vestimenta. La del caricaturista era sin dudas una mirada "desde adentro", desde la "cocina" editorial, ya que, como lo indicaba el artículo, el dibujo había sido hecho en la oficina de redacción mientras el canillita esperaba la edición del día para repartir en la ciudad.

Esta representación del periodista como obrero -incluso, a veces, atribuida a otros productores culturales- se hallaba presente en revistas y, sobre todo, en diarios y periódicos desde principios del siglo. En 1902, Luz y Sombra, el semanario literario de Vicente Romero Larré y Víctor Morera Sobré, se había referido a los "obreros del pensamiento" y en 1910 el diario Bahía Blanca dirigido por Francisco Cordero y Urquiza había afirmado:

Los periodistas somos como los bueyes: laboriosos y sufridos. Solo que nuestra coyunda es aún más pesada que la que soporta el cuadrúpedo. Más que éste, sentimos la "picana" y muchas veces sin "mosquear". Este es nuestro destino. Amén (BAHÍA BLANCA, 11 jul. 1909, p. 4).

Si bien es cierto que esta imagen era utilizada para valorizar la escritura como trabajo y para dar cuenta de las nuevas relaciones que imponía el mercado periodístico, la pluralidad de sentidos que emergía de ella se prestaba para diferentes usos que dependían del posicionamiento de los agentes sociales. Así, mientras para los mismos periodistas, abocados al logro de derechos laborales y a la organización de asociaciones profesionales ${ }^{24}$ constituía una forma de posicionarse frente a la sociedad y a los propios empresarios del rubro, para esa "aristocracia del talento" que conformaban los literatos, la calificación de

23 José Cors era uno de los canillitas que regularmente vendía en las calles Arte y Trabajo. Enterados de su talento, los empleados de la revista promocionaron en sus páginas y gestionaron ante la municipalidad el otorgamiento de una beca para que Cors pudiera iniciar sus estudios de arte en la ciudad y perfeccionar así sus capacidades. Los años subsiguientes, el semanario de Janelli publicaría en repetidas ocasiones las caricaturas de su protegido, informando a los lectores sobre sus avances. Al momento de realizar esta caricatura, la primera publicada en la revista, Cors tenía tan sólo 14 años. (AGESTA, 2010).

24 En 1904, se había conformado el Círculo de la Prensa de Bahía Blanca cuyos principales objetivos eran fomentar y sostener la unión y los intereses morales y materiales de quienes participaran en la actividad periodística, aunar voluntades en el apoyo de iniciativas benéficas para la región y ejercer la protección mutua entre sus asociados. En este sentido, se creaba una Caja de Socorros y Subsidios, se protegía a sus miembros ante posibles arbitrariedades y se contemplaban mecanismos para socorrer a los socios que se encontraran sin trabajo, asegurándoles así la continuidad en el desempeño profesional (ESTATUTOS..., 1904). 
"obrero" iba en desmedro de su pretendida autonomía y del desarrollo imaginativo que su tarea suponía. El artesano, desde su punto de vista, repetía una y otra vez procedimientos mecánicos donde poco intervenían la inspiración y la originalidad. El poeta, incomprendido habitante del universo de la idea, no podía concebirse a sí mismo en estos términos. Héroe, cruzado, redentor, intérprete divino, tales eran las representaciones que de él circulaban en las producciones poéticas de las revistas literarias e ilustradas.

\title{
De poetas y de locos
}

\author{
Vive en los mundos que su mente crea, \\ y en alas de su excelsa fantasía, \\ lánzase heroico a la gentil porfía \\ caballero cruzado de la idea. [...] \\ Él tiene, como Cristo, su calvario, \\ y de la gloria eterno visionario \\ sólo ante Dios su majestad inclina. \\ (Ecos, 12 nov. 1910, p. 23).
}

El artista romántico definido de esta manera no se hallaba, sin embargo, libre de contradicciones y no debe sorprendernos que quienes asumían el papel de "caballeros de la idea" aparecieran unos años más tarde en los anuncios publicitarios promocionando sus estudios contables o jurídicos. Este era el caso, por ejemplo, del contador público Gabriel Ganuza Lizarraga, colaborador literario frecuente de las revistas bahienses. Si bien es cierto que la vida bohemia constituyó para muchos de estos escritores tan sólo una etapa ligada a las rebeldías y los sueños de juventud, ${ }^{25}$ no puede soslayarse que en la mayoría de los casos ésta respondía a cierta concepción de la escritura y de los artistas muy marcada por la impronta del modernismo. Es decir, la tensión entre la pretendida autonomía y la realidad de una ciudad donde no existía la posibilidad de publicar las obras fuera del circuito periodístico, ubicaba al poeta en una difícil posición que lo obligaba a transgredir esa misma autonomía y a atentar contra los principios del espiritualismo. Así, las reiteradas críticas al "mercantilismo" imperante en Bahía Blanca, colisionaban con su participación en el mundo de los negocios, y su impugnación de la política tal como se ejercía en el ambiente local, no impediría que muchos de ellos se enrolaran en los principales partidos (Unión Cívica Radical o Partido Conservador) y ocuparan, gracias a ello, cargos municipales. ${ }^{26}$

25 Jorge Rivera señala a propósito de Buenos Aires que, hacia el Centenario, los cuadros de la bohemia comenzaron a desintegrarse como consecuencia de la muerte de unos y de la asimilación de otros al ámbito docente, a la burocracia cultural, a la política o al periodismo. También la consolidación del carácter profesional de la carrera literaria y las posibilidades de ascenso social explicarían el "aburguesamiento" de muchos de ellos (RIVERA, 1971).

26 Fue el caso de, por ejemplo, Víctor Morera Sobré (UCR-Club Hipólito Yrigoyen), Francisco Cordero y Urquiza (Fuerzas Conservadoras) y el mismo Francisco Pablo de Salvo (Partido Conservador). Aunque el mito de la "torre de marfil" ya ha 
Los valores de la literatura modernista que definían al poeta no resultaban, sin embargo, cuestionados en el seno de la comunidad intelectual. La visita de Rubén Darío en 1898 y la llegada de literatos, libros y revistas de otras partes del país, ${ }^{27}$ había contribuido a la propagación y consolidación de estas ideas. Tal como el poeta nicaragüense que había hecho de la creación de revistas literarias y de la intervención periodística estrategias de difusión de su ideario estético, los escritores bahienses fundaron sus propios proyectos editoriales donde aparecían sus poemas, crónicas o narraciones. Una diferencia importante separaba, con todo, al primero de los segundos: mientras para Darío la tarea periodística constituía un complemento de su obra poética editada en libros, ${ }^{28}$ para la mayoría de los autores locales éste era el único medio de publicación posible. Por ello, si bien, como afirman Beatriz Sarlo y Carlos Altamirano, aún no era posible hablar de profesionalización de la escritura en términos económicos, la existencia de una "conciencia del oficio" en torno a la cual se construían las nuevas identidades sociales, permitía entrever el desarrollo de un proceso de configuración de comunidades profesionales (ALTAMIRANO; SARLO, 1997, p. 161-200). Los literatos, nucleados en torno a los semanarios, fueron construyendo así una representación compartida de sí mismos y de su posición social. Vestimenta, actitudes y espacios de sociabilidad, se volvieron tan importantes como la práctica escrituraria en la definición de la imagen del poeta. La exageración de la individuación y el rechazo a la moral burguesa se convertían en elementos de distinción que configuraban la figura de "los raros". ${ }^{29}$ En sus "Comentarios alegres", Samuel Méndez (seudónimo de Fernando García Monteavaro), mencionó los principales literatos que constituían la bohemia bahiense:

Ayer en la estación del Sur había una escena tocante. Se marchaba el caricaturista Ranfagni y fueron a despedirle unos cuantos bohemios escrachados por el viajero.

Estaba Del Piero, el de las águilas rojas; Eneas, que tiene una opinión fraudulenta de la poesía, al decir de Valverde, el editor de la guía; De Salvo, el místico, que confunde observación con curiosidad y en todo mete las narices; Sigfrig, el de las hadas negras que cabalgan en corceles de cristal... y así por el estilo...

sido revisado por investigadores como Julio Ramos, en este caso nos encontramos con una participación política directa de los escritores, no sólo desde el punto de vista ideológico, sino explícitamente partidario.

27 Hemos trabajado en otras ocasiones sobre la circulación de personas y de bienes (AGESTA, 2013, p. 67-93) y, en particular, sobre la visita de Rubén Darío a Bahía Blanca (AGESTA, 2012).

28 Carlos Battilana observa que para Rubén Darío la inscripción periodística suponía la posibilidad de ingresar en una nueva esfera de escritura que, por su carácter masivo, implicaba una relación diferente con el público. En sus palabras "detentar la destreza de la escritura periodística, significa para Darío adueñarse de un discurso central y moderno. Y significa algo más: utilizar ese discurso con el fin de hacer una referencia diferida al discurso poético." (BATTILANA, 2001, p. 169-175).

29 Mónica Bernabé analiza de qué manera los textos y de la presencia de Rubén Darío en Buenos Aires contribuyeron a forjar a idea de "una aristocracia del talento" donde confluían la vida del artista y su trabajo de escritura. Su objetivo era edificar "una posición de aislamiento social de la cual se desprende el torremarfilismo como ejercicio de un dandismo de tipo baudelairiano". La figura del "raro", consolidada a partir de la obra homónima de Darío, era producto de "la asimilación de una serie de figuras que formaban parte del imaginario del artistas europeo hacia fines del diecinueve" y se transformó en la imagen de referencia también para los escritores argentinos (BERNABÉ, 2006). 
Como eran muchos y no cabían en el comedor del tren, se apostaron frente a la ventanilla donde se sentó Ranfagni y comenzar a beber aperitivo que éste les alcanzaba en sendos vasos...

¡Lo arruinaron al pobre!...

El ultimo adiós fue emocionante, conversos en todos los idiomas y disparates de todos los calibres..

Pero los bohemios quedaron tan triste que, de consuno, decidieron sacrificar sus melenas y realizar otros votos no menos importantes [...] (ECOS, 8 abr. 1911, p. 4-5).

Además de mencionar los nombres de Del Piero, Eneas, De Salvo y Sigfrig, esta breve descripción humorística apelaba a varios elementos propios de la comunidad artística del momento: erudición y cosmopolitismo traducido en el plurilingüismo, desbordes imaginativos, misticismo y artificiosidad lírica pero también largas melenas y consumo abundante de bebidas alcohólicas. "Escenas de la vida bohemia", narración cómica de Mario Lafuente también aparecida en $E \cos$ (ECOS, 21 jan. 1911, p. 11), agregaba a estas características la ambigüedad de sus relaciones con el Estado (la bohemia ignorada y, a la vez, oficial), el culto a la tristeza, la pasión por el juego, el hambre y la pobreza endémicas y la apelación constante a la cultura clásica. Todas ellas configuraban un perfil de intelectual que funcionaba como retrato de los literatos pero también como horizonte de referencias para los jóvenes escritores.

A estas imágenes discursivas que se multiplicaban en las páginas de las revistas, Ecos sumó representaciones gráficas de cada uno de estos personajes que, desde la "risa amable", ${ }^{30}$ reforzaban y enriquecían el modelo vigente. Un año antes, en 1910, Hoja del Pueblo, el periódico de Juan Franzetti, ya había caricaturizado a Monteavaro utilizando algunos de los recursos que luego se reiterarían en los dibujos de Ecos. [Fig. 6] La caricatura -moderna en su factura de negros y blancos plenos y en su tratamiento sintético de la línea- mostraba al poeta tañendo la lira con expresión melancólica, mientras en el extremo superior izquierdo una mujer llamativamente fea le hacía "pito catalán". Sobre García Monteavaro, la luna personificada lloraba con gesto de disgusto; más abajo, un perro parado junto a una esquemática revista Proyecciones aullaba al bardo. Al pie del cuadro, dos versos rezaban: "Mientras él canta á la beldad soñada/ Véase á la luna en lágrimas bañada".

30 Utilizamos el concepto de "risa amable" para diferenciar las representaciones caricaturescas cuya finalidad era homenajear con un tono afectivo y benigno a algunos personajes locales de aquéllas que pretendían ridiculizar y desacreditar con agresividad a los retratados. Mientras esta "risa satírica" y, en ocasiones, cruel de la caricatura y los chistes gráficos era la modalidad elegida para intervenir simbólicamente en las luchas políticas y en los enfrentamientos partidarios, la "risa amable" era utilizada a propósito de aquellos temas o personas sobre los que se asentaba la estabilidad del orden cultural, económico y social bahiense 


\section{Figura 6 - García Monteavaro}

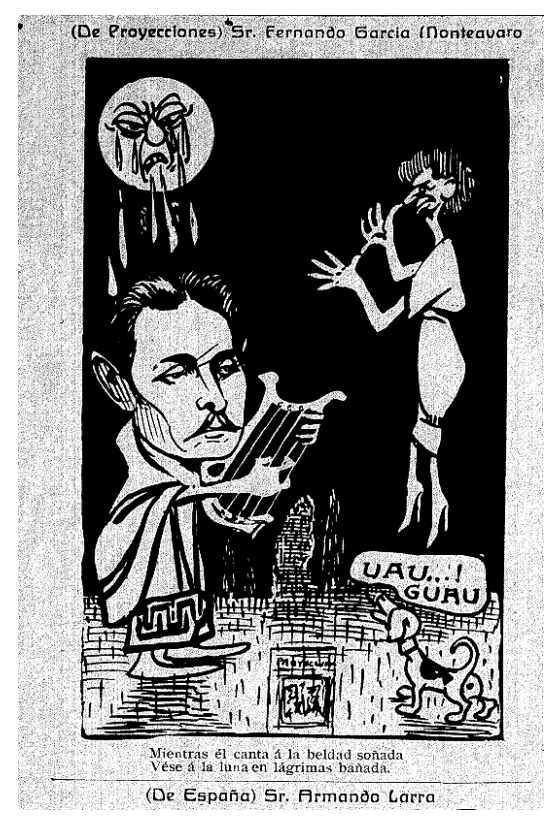

Fonte: Hoja del Pueblo, 1 set. 1910, p. 15.

Imagen y texto generaban la comicidad por contraste: la musa que inspiraba al poeta no era más que un personaje feo y grotesco que sólo la imaginación del enamorado podía transformar en objeto de adoración y que, para colmo de males, parecía evitarlo con sorna. La luna, por su parte, mentada en tantos poemas, lloraba de irritación, no ante la tristeza de los versos, sino a su tortuoso melodramatismo que permanentemente la invocaba. El artista, ajeno a todo, proseguía inmutable su canto ataviado con los atuendos propios del aedo antiguo. Sin dudas, se trataba de una representación que de la mirada periodística recuperaba los atributos que los mismos poetas reconocían como propios y los volvía en su contra de un modo burlón. 
Figura 7 - Leopoldo Eneas

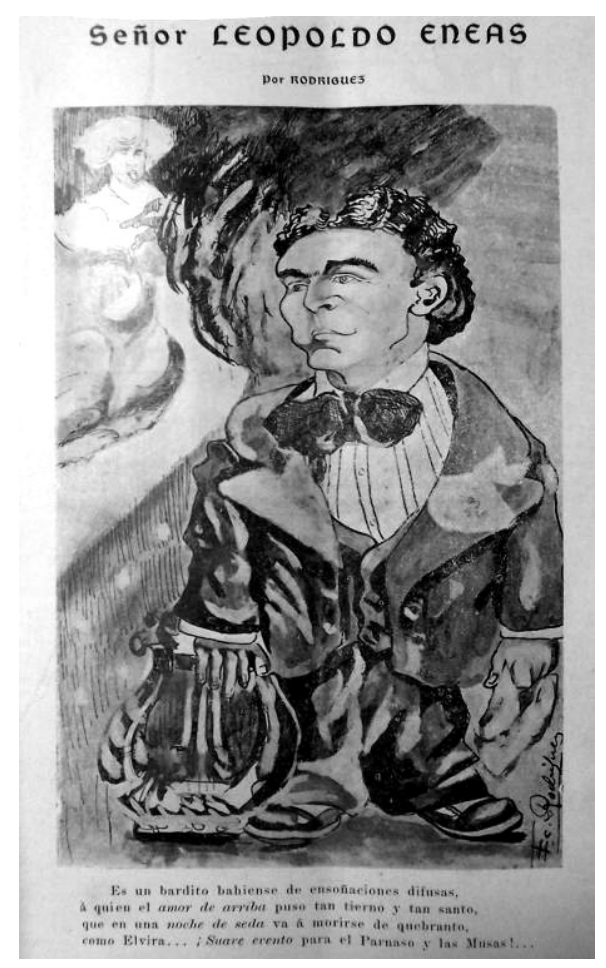

Fonte: Ecos, 1 abr. 1911, p. 13.

La lira, la musa y la actitud romántica; a los tres apeló también el caricaturista Francisco Rodríguez para retratar a Leopoldo Eneas en Ecos. [Fig. 7] Aunque similar en sus elementos compositivos, la intención se revelaba como radicalmente diferente de la anterior. La musa ya no aparecía ridiculizada, sino bajo la forma de una joven de la época que emergía de las nubes del pensamiento; la mirada de Eneas, aunque igualmente absorta, denotaba dignidad e idealismo; en sus manos la lira y papel, la inspiración y la escritura, se complementaban como partes indisociables del trabajo intelectual. Desde el tratamiento de las formas mucho más vinculadas a una estética decimonónica donde el uso de matices, luces y sombras aseguraba un mayor realismo - hasta la cuarteta que las acompañaba, ${ }^{31}$ la imagen evidenciaba afecto (el bardito) y simpatía frente al personaje y su trabajo. El detalle humorístico introducido por la vestimenta en el caso de Monteavaro, fue, asimismo, suprimido en aras de esta nueva finalidad de homenaje. La ropa de Leopoldo Eneas tenía

31 "Es un bardito bahiense de ensoñaciones difusas,/ á quien el amor de arriba puso tan tierno y tan santo,/ que en una noche de seda va á morirse de quebranto,/ como Elvira... ¡Suave evento para el Parnaso y las Musas!..." 
menos una carga simbólica que un propósito de registro: en especial el amplio lazo y el pañuelo en el bolsillo exterior del saco se convertirían en componentes infaltables del guardarropa bohemio que también fueron incorporados a la caricatura del poeta "decadente" Américo del Piero. (Fig. 8) La melena que había señalado Samuel Méndez y el fino bigotillo al estilo del de Monteavaro, se presentaban aquí como otras marcas de la identidad del artista sobre su cuerpo, mientras, una vez más, el perro desconsolado introducía el factor humorístico de la representación.

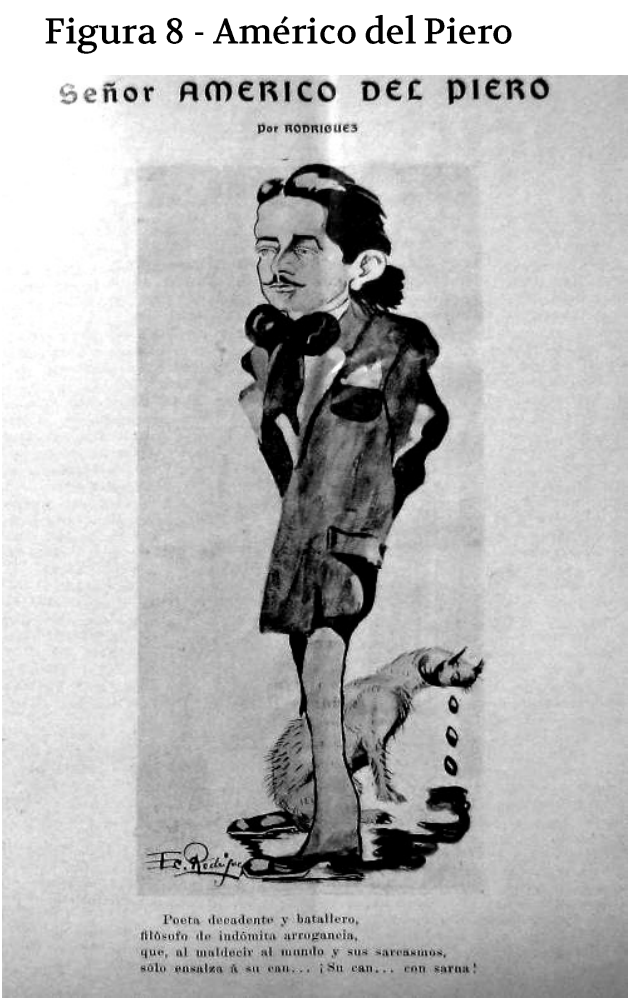

Fonte: Ecos, 4 fev. 1911, p. 14.

\section{Conclusiones}

Poetas y periodistas formaron parte del proceso de autonomización de la escritura que había tenido lugar en la ciudad de Bahía Blanca y en el resto del país asociado a la modernización económica, social, política y cultural desde fines del siglo xIX. Esta autonomía, aunque nunca plena, se erigió en principio rector del funcionamiento del incipiente campo cultural local y fue en torno a ella que se concibieron las nuevas 
identidades sociales de los hombres de letras. La profesionalización, si bien se convirtió en un horizonte de expectativas compartido, no presentó las mismas condiciones de posibilidad para todos ellos. La prensa, ampliamente desarrollada desde sus orígenes decimonónicos, había pasado de estar al servicio de la política a transformarse en el "cuarto poder" gracias a la utilización de nuevas técnicas y procedimientos de trabajo y a la paulatina diversificación de formatos y de géneros que le permitió acceder a distintas fracciones de un público en crecimiento, incorporándose, así, al mercado moderno de bienes simbólicos.

La proyección de la lógica mercantil al ámbito de la cultura conllevaría una transformación de las representaciones que de sí mismos y de los demás tenían los periodistas y los escritores. Dentro del heterogéneo campo que componían los primeros, se diferenciaron claramente dos figuras: la del trabajador de prensa y la del empresario. En textos e imágenes, el periodista fue caracterizado como un obrero que, al igual que sus pares en la fábrica, se hallaba sometido a las arbitrariedades de sus superiores y debía cumplir con las exigencias que le imponía el mercado. La escritura se transformaba en un bien económico y el escritor, en un asalariado. Las imágenes de los empresarios, por su parte, variaron de acuerdo al punto de vista del dibujante y del medio abarcando una gama que iba desde el mercenario inescrupuloso hasta el joven emprendedor y progresista. Con una intención crítica o elogiosa, en ambas el empresario aparecía más como administrador que como intelectual.

Los literatos, atravesados por la sensibilidad modernista, no podían sino rechazar la sujeción del trabajo intelectual a los mecanismos y ritmos de la economía, aún cuando ellos mismos encontraran en la prensa -en especial, en las revistas culturales- el único espacio posible de intervención y de publicación de sus obras. En efecto, la ausencia de casas impresoras dispuestas a asumir los riesgos monetarios de editar a los autores locales, impedía que la literatura se volviera un medio de subsistencia. Así, aunque insertos en el periodismo, los escritores buscaron distanciarse de él. Las representaciones del "poeta", fundadas en la exaltación romántica de su actividad, evitarían las referencias al mundo laboral para centrarse en la dimensión espiritual de su tarea. Místicos, mártires, demiurgos o redentores, eran las imágenes que de ellos circulaban en poemas, narraciones y caricaturas. La fórmula que los definía se hallaba en el encuentro de la erudición, la inspiración y el sentimiento. Sus vínculos con la tradición grecorromana y su conocimiento de idiomas clásicos y modernos, los transformaban en una "aristocracia del talento", unida por los códigos y las prácticas de la bohemia, cuyo cosmopolitismo y refinamiento legitimaban su posición simbólica dominante ante el resto de la sociedad. 


\section{Fontes Documental}

ARTE Y TRABAJO. Bahía Blanca, p. 22, 31 jan. 1920.

ARTE Y TRABAJO. Bahía Blanca, año 3, n. 51, p. 19, 20 fev. 1918.

ARTE Y TRABAJO. Bahía Blanca, año 8, n. 112, p. 18, 31 maio 1923.

ARTE Y TRABAJO. Bahía Blanca, año 3, n. 54, p. 26, 30 abr. 1918.

ARTE Y TRABAJO. Bahía Blanca, año 3, n. 55, p. 19, 20 abr. 1918.

BAHÍA BLANCA. Bahía Blanca, año 4, n. 1063, p. 4, 11 jul. 1909.

ECOS. Bahía Blanca, año 1, n. 2, p. 23, 12 nov. 1910.

ECOS. Bahía Blanca, año 1, n. 5, p. 21, 3 dez. 1910.

ECOS. Bahía Blanca, año 1, n. 12, p. 11, 21 jan. 1911.

ECOS. Bahía Blanca, año 1, p. 14, 4 fev. 1911.

ECOS. Bahía Blanca, año 1, n. 18, p. 6, 4 mar. 1911.

ECOS. Bahía Blanca, año 1, n. 22, p. 4, 1 abr. 1911.

ECOS. Bahía Blanca, año 1, p. 13, 1 abr. 1911.

ECOS. Bahía Blanca, año 1, n. 23, p. 4-5, 8 abr. 1911.

ESTATUTOS y reglamentos del Círculo de la Prensa de Bahía Blanca. Bahía Blanca: Tipografía Galiani, 1904.

HOJA DEL PUEBLO, p. 15, 1 set. 1910.

REVISTA COMERCIAL DE BAHÍA BLANCA. Bahía Blanca, año 4, n. 119, p. 15, 8 fev. 1905.

\section{Referencias}

AGESTA, María de las Nieves. El barómetro de la cultura. Luz y sombra: intelectuales y crítica en Bahía Blanca, 1902. In: JORNADAS INTERDISCIPLINARIAS DEL SUDOESTE BONAERENSE:Cuestiones políticas, socioculturales y económicas en el sudoeste 
bonaerense, 4., 2007, Bahia Blanca. Actas... Bahía Blanca: Universidad Nacional del Sur, 2007. p. 149-156.

AGESTA, María de las Nieves. Los recorridos de la cultura. Operadores, intermediarios y tránsitos culturales en el periodismo bahiense de principios del siglo xx. In: CERNADAS DE BULNES, Mabel; ORBE Patricia. Itinerarios de la prensa: cultura política y representaciones en Bahía Blanca, siglo XX. Bahía Blanca: EdiUNS, 2013. p. 67-93.

AGESTA, María de las Nieves. Muñecas rusas: lecturas y lectores en la prensa ilustrada bahiense de las primeras décadas del siglo XX. In: HISTORIA DE LA PATAGONIA: LAS JORNADAS, 4., 2010, Río Negro. Actas... Río Negro: Universidad Nacional de Río Negro, 2010.

AGESTA, María de las Nieves. Proyecciones en imágenes: prensa ilustrada y cultura visual en el proceso de modernización de Bahía Blanca (1909-1910). 2009. Tesis (Maestría en Sociología de la Cultura y Análisis Cultural) - Instituto de Altos Estudios Sociales, Universidad de San Martín, 2009.

AGESTA, María de las Nieves. Rubén Darío en la "ciudad de la mar". La visita del poeta nicaragüense a Bahía Blanca y su impronta en la constitución del campo intelectual local a principios del siglo XX. In: JORNADAS DEL DEPARTAMENTO DE HISTORIA, 6., 2012, Mar del Plata. Acatas... Mar del Plata: Facultad de Humanidades de la Universidad de Mar del Plata, 2012.

ALTAMIRANO, Carlos. Términos críticos de sociología de la cultura. Buenos Aires: Paidós, 2002.

ALTAMIRANO, Carlos; SARLO, Beatriz. La Argentina del centenario: campo intelectual, vida literaria y temas ideológicos. In: _ _ _ _. Ensayos argentinos: de sarmiento a la vanguardia. Buenos Aires: Ariel, 1997. p. 161-200.

BATTILANA, Carlos. La construcción de un lector. Rubén Darío desde 1893 a 1898. In: FIN(ES) DE SIGLO Y MODERNISMO: CONGRESO INTERNACIONAL, 1996. Buenos Aires-La Plata. Actas... Palma: Universitat de les Illes Balears, 2001. p. 169-175.

BAUMAN, Zygmunt. Legisladores e intérpretes: sobre la modernidad, la posmodernidad y los intelectuales. Bernal: Universidad Nacional de Quilmes, 1997.

BERNABÉ, Mónica. Vidas de artista: bohemia y dandismo en Mariátegui, Valdelomar y Eguren (Lima, 1911-1922). Rosario: Beatriz Viterbo-IEP, 2006.

CHARLE, Christophe. El nacimiento de los "intelectuales" 1800-1900. Tradução de Heber Cardos. Buenos Aires: Nueva Visión, 2009. 
CHARTIER, Roger. La historia cultural redefinida: prácticas, representaciones, apropiaciones". Punto de Vista, Buenos Aires, n. 39, p. 43-48, 1990.

GARCÍA, Germán. El periodismo. Testimonio y pasión de una época. In: 1828-11 de abril1978. sesquicentenario de la fundación de Bahía Blanca. Bahía Blanca: La Nueva Provincia, 1978. p. 83.

LAERA, Alejandra. Cronistas, novelistas: la prensa periódica como espacio de profesionalización en la Argentina (1880-1910). In: MYERS, Jorge. Historia de los intelectuales en América Latina: I. La ciudad letrada, de la conquista al modernismo. Buenos Aires: Katz, 2008. p. 495-522.

MATIJEVIC, Nicolás. Imprenta bahiense. Bahía Blanca: Universidad Nacional del Sur, 1978.

MONTALDO, Graciela. La sensibilidad amenazada: fin de siglo y modernismo. Rosario: Beatriz Viterbo editora, 1994.

PIERINI, Margarita; CAMPODÓNICO, Horacio; CILENTO, Laura; GRILLO, Maria Victoria; LABEUR, Paula. La novela semanal (Buenos Aires, 1917-1927). Madrid: CSIC, 2004.

RAMA, Ángel. La ciudad letrada. Santiago de Chile: Tajamar, 2004.

RAMOS, Julio A. Desencuentros de la modernidad en América Latina: literatura y política en el siglo XIX. México: Fondo de Cultura Económica, 2003.

RIVERA, Jorge B. El escritor y la industria cultural. Buenos Aires: Atuel, 1998.

RIVERA, Jorge B. Los bohemios. Buenos Aires: CEAL, 1971.

ROCCHI, Fernando. El péndulo de la riqueza: la economía argentina en el período 1880-1916. In: TANDETER, Enrique; GOLDMAN, Noemi. Nueva historia argentina: el progreso la modernización y sus límites (1880-1916). Buenos Aires: Sudamericana, 2000. p. 15-69.

SARLO, Beatriz. El imperio de los sentimientos. Buenos Aires: Norma, 2000.

TERÁN, Oscar. El pensamiento finisecular (1880-1916). In: TANDETER, Enrique; GOLDMAN, Noemí. Nueva historia Argentina: el progreso la modernización y sus límites (1880-1916). Buenos Aires: Sudamericana, 2000. p. 327-364.

TUMA, Mercedes P.; BERMEJO HURTADO, Haydée; BLANCO DE ANTA, Ana M. Los primeros textos literarios impresos en Bahía Blanca (poetas y narradores). Cuadernos del Sur, Bahía Blanca, n. 15, p. 151-175, 1982. 